\title{
Feasibility Study for Well pattern Encryption in Complex Fractured Block Reservoirs--Taking the Liu 90 South Fault Block in the Jidong Oilfield as an example
}

\author{
Qunyi Wang ${ }^{1}$, Yongbin Bi ${ }^{1,2}$, Tongfeng Cao ${ }^{1}$, Yang Zhang ${ }^{1}$, Dong Liu ${ }^{1}$, Haiyan $\mathrm{He}^{1}$, Xuena Zhang ${ }^{1}$ \\ ${ }^{1}$ Jidong Oilfield Company, PETROCHINA, China \\ ${ }^{2}$ Northeast Petroleum University, China
}

\begin{abstract}
Jidong oilfield belongs to complex fault block reservoir, and the development has now entered into high water-cut stage. when using Well pattern encryption technology to stabilize production, it is necessary to study the feasibility of Well pattern encryption to ensure a better economic benefit. In this paper, we use theoretical analysis method, consider the influence of oil price on the calculation, improve the economic limit Well pattern density calculation formula, calculate the economic limit Well pattern density under different recovery rates, make recovery rate prediction for different Well pattern density scenarios by combining with Sherkachov's formula, and use the curve intersection method to determine the Well pattern density at the break-even point, so as to determine the economic feasibility of Well pattern encryption. The example calculations show that the use of well network encryption alone does not meet the development requirements of the Liu 90 South block and has no significant economic benefits, so a combination of twothree methods is needed to further improve the recovery rate. Numerical simulation prediction results show that the two-three combination method can improve the recovery rate by $14.54 \%$, accumulate $28.88 \times 10^{4} \mathrm{t}$ of oil increase and increase revenue by $678,245,000$ yuan.
\end{abstract}

Keywords: complex block reservoir; well network encryption; economic limit well network density; twothree combination.

\section{Introduction}

Jidong oilfield is a complex block oilfield and is now in the high water content development stage. Subsequent development adjustments usually take the form of well network encryption to improve the development level and economic efficiency. A large number of practices show that too small a Well pattern density leads to insufficient well control reserves, which will affect the development level of the field; too large a Well pattern density leads to high drilling investment, making the Well pattern encryption measures not economically efficient. Therefore, it is important to study the feasibility of Well pattern encryption to develop a reasonable development adjustment plan for complex block oil fields.

\section{Applying Sherkachov formula to determine the relationship between well pattern density and recovery}

\subsection{Sherkachev formula}

Whether the relationship between recovery factor and well pattern density is established correctly or not is related to the effect of infilling adjustment of well pattern. Most scholars have counted the relationship between recovery factor and well pattern density, and obtained the relationship between recovery factor and well pattern density, but most of these formulas lack practicability and universality 1 . It was not until the 1960s that the Soviet scholar Serkachev, by compiling, analyzing and studying data from the end of oil field development, condensed Serkachev's formula to more accurately characterize the mathematical relationship between well type density and recovery rate 2 .

$$
E_{R}=E_{D} e^{(-a / f)}
$$


where: ER is the ultimate recovery of the reservoir, $\%$; ED is the water displacement efficiency, $\%$; $a$ is the Well pattern index, dimensionless quantity; $f$ is the Well pattern density, Port $/ \mathrm{km}^{2}$.

The variability of different oil fields is reflected in the variation of Well pattern index and Displacement efficiency in equation (1). The Well pattern index depends on factors such as formation connectivity, oil-water flow rate ratio, and non-homogeneous characteristics of the formation, and its value integrally reflects the characteristics of the field 3 . Therefore, the key to the correct application of the Sherkachevformula is to determine the displacement efficiency and well pattern index that are consistent with the field reality.

\subsection{Method for determining the Displacement efficiency and Well pattern index a}

(1) Empirical formula method

The widely used empirical formulas include the empirical formula of the China National Petroleum Exploration and Development Institute, the Chen Yuanqian empirical formula, and the Yu Qitai empirical formula 45.

The Empirical formula of CNPC E\&P Research Institute is shown in Table 16 .

Table 1. Table of empirical formulas of CNPC E\&P Research Institute

\begin{tabular}{c|c|c|c}
\hline categories & $\begin{array}{c}\text { Number } \\
\text { of oil } \\
\text { deposits }\end{array}$ & $\begin{array}{c}\text { Fluidity / } \\
\left(10^{-3} \mu \mathrm{m}^{2} \mathrm{~g}(\mathrm{mPags})^{-1}\right)\end{array}$ & $\begin{array}{c}\text { regression } \\
\text { relation }\end{array}$ \\
\hline 1 & 13 & $300 \sim 600$ & $E_{R}=0.6031 e^{-}$ \\
\hline 2 & 27 & $100 \sim 300$ & $E_{R}=0.5508 e^{-0.0}$ \\
\hline 3 & 67 & $30 \sim 100$ & $E_{R}=0.5227 e^{-0.0 .}$ \\
\hline 4 & 19 & $5 \sim 30$ & $E_{R}=0.4832 e^{-0.0}$ \\
\hline 5 & 18 & $<5$ & $E_{R}=0.4015 e^{-0.11}$ \\
\hline
\end{tabular}

(2) Actual data regression method

Taking the logarithm of both sides of equation (1), the following equation can be obtained.

$$
\ln E_{R}=\ln E_{D}-a / f
$$

On the right-angle coordinate axis, the actual production data are regressed according to Equation (2) using the inverse of the Well pattern density as the horizontal coordinate and the natural logarithm of the recovery rate as the vertical coordinate. The slope of the regression line is the Well pattern index a of the field, and the intercept is $\ln E_{D}$.

(3) Relative permeability curve method

The Relative permeability data is first used to derive the oil Displacement efficiency, after which the Well pattern index in the Sherkachevformula is back-calculated using the current calibrated recovery of the field and the Well pattern density.

$$
a=f \times \ln \frac{E_{D}}{E_{R}}
$$

Jidong oilfield has accumulated a large amount of relative permeability data after more than 40 years of development, and the normalization of multiple relative permeability curves can represent the field characteristics and calculate the oil drive efficiency and well pattern index more accurately 78 , so this method is used to calculate the oil drive efficiency and well pattern index in this study.

\section{Method for determining the economic limit Well pattern density}

\subsection{Improved economic limit Well pattern density formula}

Appropriate well pattern encryption can bring economic benefits to the oil field, and as the number of encrypted wells increases, the economic benefits of well pattern encryption measures first increase and then decrease until no economic benefits are generated 9 . If the field reaches break-even after drilling an encrypted well, the Well pattern density of the field at that time is said to be the economic limit Well pattern density, and the average single well oil production under the economic limit Well pattern density is the economic limit single well oil production. To find the economic limit Well pattern density, it is only necessary to establish the input and output relationship of a single well based on the condition that the field reaches break-even 10 .

$$
\left[\frac{T_{i}}{T}\left(I_{d}+I_{s c}\right)+C_{w o} T_{i}\right]\left(1+R_{i n j}\right) \geq\left(P_{o i}-P_{c}-P_{t a x}\right) R_{s p}\left(\sum Q_{o i}\right)
$$

Where: $T$ is the total forecast production time, year; $I_{d}$ is the drilling investment, yuan; $I_{s c}$ is the surface construction investment, yuan; $C_{w o}$ is the oil and water well operation cost, yuan; $T_{i}$ is the forecast production time of step i oil price, $a ; R_{i n j}$ is the injection and extraction wells ratio, dimensionless; $P_{o i}$ is the step i oil price, yuan/ton; $P_{c}$ is the operation cost, yuan/ton; $P_{\operatorname{tax}}$ is the tax and management fee, yuan/ton; $R_{s p}$ is the crude oil commodity rate, $\% ; \sum Q_{o i}$ is the cumulative oil production of a single well, ton.

Equation (4) is a single-well input and output relationship equation established based on the net present value principle by considering the total cost and total income of a single well comprehensively 错误!未找到引用源。. The actual situation varies widely from field to field, and the selection of economic parameters varies, but the form of equation (4) is constant, so equation (4) has universal applicability in oil fields.

Letting both sides of equation (4) take equal signs gives the economic limit of cumulative oil production per well at a step oil price.

$$
\left(\sum Q_{o}\right)_{\lim }=\frac{\left[\frac{T}{T}\left(I_{d}+I_{s c}\right)+C_{\mathrm{woo}} T_{i}\right]\left(1+R_{b y}\right)\left(1+R_{i v j}\right)}{\left(P_{o i}-P_{c}-P_{t u x}\right) R_{s p}}
$$

By combining the geological reserves, oil-bearing area and degree of crude oil recovery, the economic limit Well 
pattern density can be deduced for different recovery rates $E_{R}$.

$$
f_{\mathrm{tim}}=\frac{N\left(E_{a}-R_{o}\right)\left(1+R_{\mathrm{wu}}\right)}{\left(\sum Q_{\mathrm{o}}\right)_{\mathrm{im}} A}+f_{\mathrm{wov}}
$$

Where: $f_{\text {lim }}$ is the economic limit Well pattern density, Port $/ \mathrm{km}^{2} ; N$ is the geological reserves of crude oil, tons; $E_{a}$ is the given recovery rate, $\% ; R_{o}$ is the degree of crude oil recovery, $\% ; R_{i n j}$ is the injection and extraction wells ratio; $f_{\text {now }}$ is the original Well pattern density, $P$ ort $/ \mathrm{km}^{2} ; A$ is the oil-bearing area of the reservoir, $\mathrm{Km}^{2}$.

\subsection{Curve intersection method to determine the economic limit Well pattern density}

The equation (6) is processed to obtain the minimum recovery rate that must be achieved for economically efficient fields at different Well pattern densities.

$$
E_{R \min }=\frac{\left(f-f_{m i n}\right)\left(\sum Q_{o}\right)_{\operatorname{tin}} A}{N\left(1+R_{w j}\right)}+R_{o}
$$

where: $E_{R \min }$ is the minimum recovery rate required for break-even at a Well pattern density $f$.

Recovery rate at Well pattern density $\mathrm{f}$ can be predicted from the Sherkachevformula.

$$
E_{R}=E_{D} e^{(-a / f)}
$$

The two curves are plotted on the same coordinates and the schematic is shown in Figure 1.

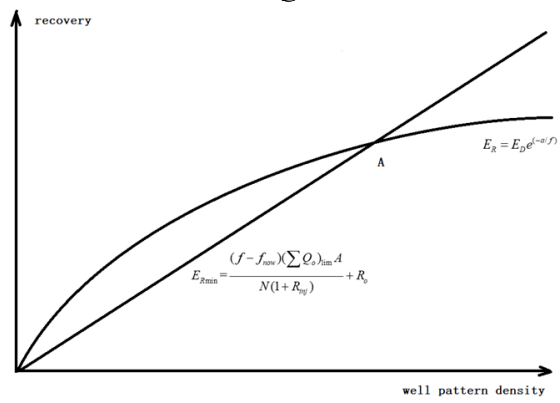

Figure 1. Curve intersection method to determine the economic limit Well pattern density

The two curves intersect at point A. The density of the Well pattern at the intersection point is the economic limit well pattern density. To the left $E_{R}>E_{R \min }$, the output of the field is greater than the input, with economic benefits. To the right of the intersection point $E_{R}<E_{R m i n}$, there is no economic benefit, the Well pattern encryption scheme is economically unreasonable.

\section{Application of the economic limit Well pattern density determination method in the Liu 90 South Fracture Block reservoir}

\subsection{Example calculations}

The geological reserve of oil reservoir in Liu 90 South Fracture Block is $1,981,400$ tons, Oil-bearing area is $1.2727 \mathrm{~km}^{2}$, using the five-point method of well placement, the number of injection and extraction wells ratio is $1: 1$, the current Well pattern density is $27.5 \mathrm{port} / \mathrm{km}^{2}$, the calibration recovery rate is $35.08 \%$; single well drilling investment is $8,500,000$ yuan, average surface construction costs is 850,000 yuan, single well average operating costs is 290,000 yuan/year, operating costs is 146 yuan/ton, tax and administration fee is 316 yuan/ton, and crude oil commodity rate is 1 ; step oil price $P_{O I}=$ $\$ 45 / \mathrm{bbl}, \quad T_{1}=2$ years; $P_{O 2}=\$ 50 / \mathrm{bbl}, \quad T_{2}=2$ years; $P_{O 3}=\$ 60 / \mathrm{bbl}$ at $T_{3}=11$ years.

According to the formula $(4) \sim(6)$, the cumulative oil production and the economic limit well pattern density are calculated.

(1) Economic Limit Cumulative oil production of single well $\sum Q_{o i}$

Following equation (1), the cumulative oil production from a single well at the economic limit under the step oil price is calculated and the results are shown in Table 2.

Table 2. Calculation result of limit cumulative oil production of single well under the step oil price

\begin{tabular}{c|c|c|c}
\hline Step oil price $P_{o i}(\$ / \mathrm{bbl})$ & 45 & 50 & 60 \\
\hline Production time $T_{i}$ (years) & 2 & 2 & 11 \\
\hline$\sum Q_{o i}$ (million tonnes) & 0.8321 & 0.5331 & 1.7062 \\
\hline
\end{tabular}

(2) Economic limit Well pattern density $f_{\text {lim }}$ at different recovery rates

On the basis of the calculated single well limit cumulative oil production, the required parameters were substituted according to equations (2) to (5) to calculate the economic limit Well pattern density under different recovery rate conditions, and the results are shown in Table 3.

\begin{tabular}{|c|c|c|c|c|c|c|c|}
\hline $\begin{array}{c}\text { Given } \\
\text { recover } \\
\text { y rate } E_{a} \\
(\%)\end{array}$ & 20 & 25 & 30 & 35 & 40 & 45 & 50 \\
\hline $\begin{array}{c}f_{\text {lim }} \\
(\text { Port } / k \\
\left.m^{2}\right)\end{array}$ & $\begin{array}{c}8.0 \\
4\end{array}$ & $\begin{array}{c}14.4 \\
9\end{array}$ & $\begin{array}{c}20.9 \\
5\end{array}$ & $\begin{array}{c}27.4 \\
0\end{array}$ & $\begin{array}{c}33.8 \\
5\end{array}$ & $\begin{array}{c}40.3 \\
0\end{array}$ & $\begin{array}{c}46.7 \\
5\end{array}$ \\
\hline
\end{tabular}

Table 3. Calculated economic limit Well pattern density for a given recovery rate

(3) Prediction of recovery rates at different Well pattern densities using the Sherkachevformula

The reservoir development information of the Liou 90 South Block is complete, and the Displacement efficiency of the block is 0.58 using relative permeability curve method, the current Well pattern density is 27.5 Port $/ \mathrm{km}^{2}$, the calibrated recovery rate is $35.08 \%$, and The value of the Well pattern index $a$ was calculated as 13.83 using 
Sherkachov's formula.

$$
E_{R}=0.58 e^{(-1-38 / f)}
$$

Different Well pattern encryption schemes were considered for the reservoir and the final recovery was predicted using the Sherkachov formula and the results are shown in Table 4.

Table 4. Recovery at different well pattern density predicted by Sherkachov's formula

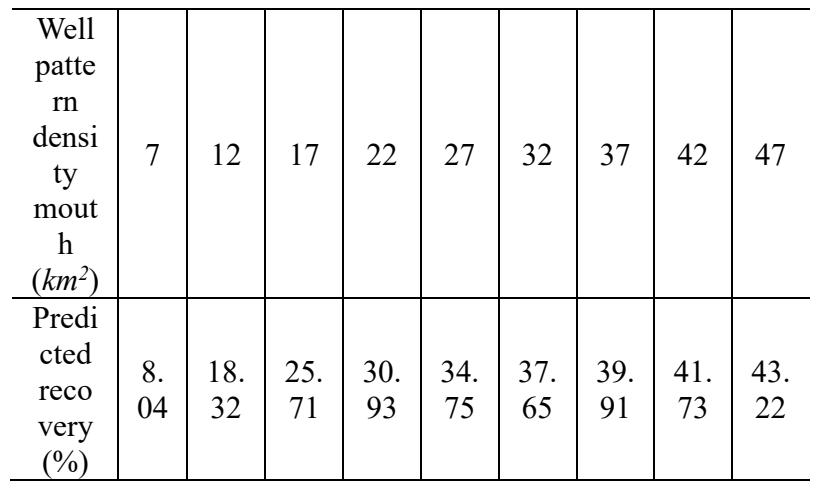

(4) Curve intersection method to determine the economic limit Well pattern density of oil fields

With the Well pattern density as the horizontal coordinate and the recovery rate as the vertical coordinate, the economic limit Well pattern density curves for different given recovery rates and the predicted recovery rate curves for different Well pattern scenarios are plotted respectively.

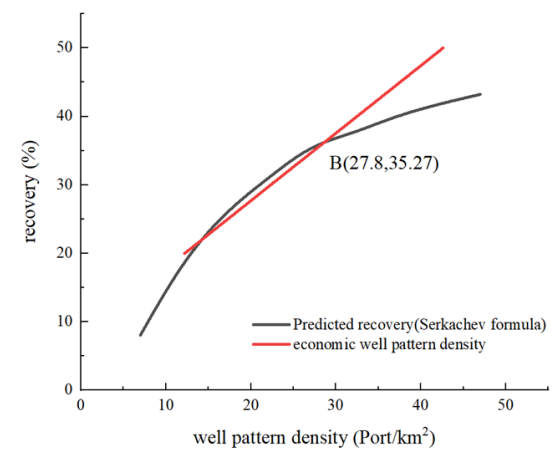

Figure 2. Curve intersection method to determine the economic limit Well pattern density

The curves in Figure 2 intersect at point B. Using MATLAB software, the coordinates of the intersection point are calculated as $(27.8,35.27)$, which means that the economic limit well network density of the field is 27.8 Port $/ \mathrm{km}^{2}$ and the predicted recovery rate of the field under this well pattern density is $35.27 \%$. The current well network density is close to the economic limit well pattern density, and the well pattern encryption within a reasonable range has limited value to improve the recovery rate and poor economic benefits.

\subsection{Recommended Measures}

The economic limit well pattern density of complex fault block reservoir in South Liu 90 was determined to be 27.8 Port $/ \mathrm{km}^{2}$. The analysis shows that the economic feasibility of well pattern infilling is not high, so it is suggested to adopt two-three combination method to enhance oil recovery. The Well pattern encryption scheme and chemical flooding scheme are designed according to the actual situation of the reservoir, and the development index is predicted by numerical simulation.

(1) Prediction of the effect of the two-three combination method to improve recovery

On the basis of studying the distribution of remaining oil in the target area, the well pattern is first optimized, then the binary system of cluster table is injected with an injection volume of $0.253 \mathrm{PV}$, and the subsequent development indexes are predicted by using CMG software. The results are shown in Fig. 3.

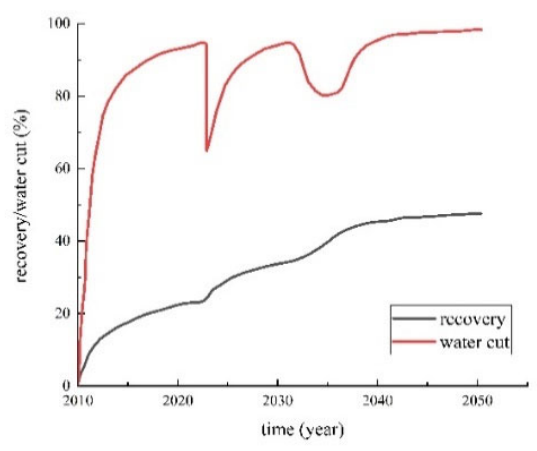

Figure 3. Development indexes of a two-three combination programme

The curve in Figure 3 shows that after the implementation of the two-three combination program, the recovery rate of the whole area reached $49.62 \%$, the recovery rate improvement value was $14.54 \%$, and the cumulative oil increase was $28.88 \times 10^{4} \mathrm{t}$, which is a good development effect.

(2) Analysis of the economic feasibility of the two-three combination option

The mass concentration of both polymer and surfactant is $1500 \mathrm{mg} / \mathrm{L}$. The unit price of polymer is 11,000 yuan/ton, and the unit price of surfactant is 20,100 yuan/ton. Considering all economic parameters, The calculation results of oilfield development index are shown in Table 5.

Table 5. Calculation of economic index

\begin{tabular}{c|c|c|c}
\hline $\begin{array}{c}\text { Well pattern } \\
\text { encryption } \\
\text { costs (yuan) }\end{array}$ & $\begin{array}{c}\text { Chemical } \\
\text { drive cost } \\
\text { (yuan) }\end{array}$ & $\begin{array}{c}\text { Measure } \\
\text { revenue } \\
\text { (yuan) }\end{array}$ & $\begin{array}{c}\text { Input- } \\
\text { output } \\
\text { ratio }\end{array}$ \\
\hline 138797700 & 116693400 & 678245000 & $1: 2.65$ \\
\hline
\end{tabular}

As can be seen from Table 5, the field revenue after the measures reached 67824.50 with an input-output ratio of 1:2.62. This indicates that the two-three combined measures can bring greater economic benefits to the Liu 90 South fault block, while the recovery rate improvement value reached $14.54 \%$ and the oil increase of $28.88 \times 10^{4} t$, 
which also meets the development requirements.

\section{Conclusion}

(1) The method of determining the economic limit well network density for complex block reservoirs is proposed. According to the input and output relationship in oilfield development, this paper considers more comprehensive economic parameters, improves the previous formula, innovatively derives the formula for the economic limit well network density under the step oil price, and combines the Sherkachov formula to determine the intersection of the two curves as the economic limit well network density of the oilfield.

(2) Taking the complex fault block reservoir of South Liu90 in Jidong Oilfield as an example, the feasibility of well network encryption is studied. The results show that the economic benefits in this block are not obvious if only well network encryption is used, so it is recommended to use two-three combination method to further improve the recovery rate. The Development Index of numerical simulation prediction shows that the two-three combination method can increase the recovery rate by $14.54 \%$, accumulate $28.88 \times 10^{4} \mathrm{t}$ of oil and create economic benefits of 678245000 yuan. The method studied in this paper can provide a basis for the adjustment of the development scheme in the high water-bearing stage of complex block reservoirs, with simple calculation and high practicality.

\section{References}

1. Zhang W. Research on the calculation method of Well pattern density under the influence of comprehensive factors [D]. Changjiang University, 2012.

2. Hou Jianfeng,Hu Yafei,Liu Chang,Zhao Hui,Wei Tao. Method for determining economic limit and reasonable Well pattern density in water-driven reservoirs [J]. Xinjiang Oil and Gas, 2018, 14(03): $53-57+4$.

3. Dou Zhidong, Li Shunying, Zhang Meiju, Wu Qiaoling, Zhang Huiqin, Chen Xiaoguang. Research and application of Sherkachov formula in $\mathrm{Hu} 7 \mathrm{South}$ Fracture Block [J]. Inner Mongolia Petrochemicals, 2013, 39(13): 129-130.

4. Geng Zhanli, An Guirong, Zhou Wensheng, Xu Jiafeng, Zhang Wei, Deng Jiuguo. Study on the relationship between Well pattern density and recovery rate in offshore thick oil fields $[\mathrm{J}]$. China Offshore Oil and Gas, 2012, 24(03): 35-37.

5. Yu Q-T. A method for calculating reasonable and limiting Well pattern densities in water-driven sandstone reservoirs [J]. Petroleum Exploration and Development, 1986(04): 49-54.

6. Yu, Cheng-Long, Li, Hui-Min, Zhao, Min, Luo, ChiHui. Research on the calculation method of reasonable number of wells for Well pattern encryption in water-driven oil field [J]. Rocky oil and gas reservoirs, 2011, 23(01): 111-113.
7. Zhang Bengqiang, Xue Guoqing, Tang Mingguang, Wang Shuai, Chen Lin. Research on the evaluation method of extreme Well pattern density in offshore oil fields [J]. Natural Gas and Petroleum, 2019, 37(04): 67-72.

8. Zou Cunyou, Han Daquang, Sheng Haibo, Wang Ping, Zhang Aidong. Exploration of a method to establish the relationship between recovery rate and Well pattern density [J]. Oil and Gas Geology and Recovery, 2010, 17(04): 43-47+114.

9. Huang Jinshan. A new method for calculating economic limit Well pattern density in oilfield [J]. Oil and Gas Geology and Recovery, 2013, 20(03): 5355+59+114-115.

10. Zhu Wenjuan, Yu Gaoming, Yan Weifeng, Zhang $\mathrm{Na}$,Chai Junliang,Wang Delong. Determination of economic limit Well pattern density in oilfield [J]. Broken Block Oil and Gas Field, 2008(04): 66-67+75.

11. Zhang Shulin, Huang Yaoqin. Net present value method--a new method for calculating economic limit Well pattern density [J]. Geological Science and Technology Information, 2004(01): 78-80. 